\title{
Effects of medial thalamic damage on initiation of movement and learning
}

\section{H. VANDERWOLF, University of Western Ontario, London, Ont., Canada}

Rats with large medial thalamic lesions fail to avoid shock but perform relatively well in a shock-motivated brightness-discrimination task. The rats are slow to initiate exploratory behavior and slow to move from a small unfamiliar platform to a familiar table placed 3 in. away, although they perform normally when movements have begun. The results suggest that the medial thalamus plays a role in the triggering of movement apart from any role it may have in learning or the coordination of movement.

Extensive destruction of the medial thalamic nuclei produces a severe deficit in both acquisition and retention of avoidance behavior in tests requiring bodily movement (Cardo, 1961; Delacour et al, 1966; Thompson, 1963; Vanderwolf, 1962, 1963). This effect has been attributed to malfunction of a mechanism which normally initiates voluntary movement (Vanderwolf, 1962). However, medial thalamic lesions also impair performance in complex mazes (Delacour et al, 1966; Gross et al, 1965; Warren \& Akert, 1960), suggesting poor learning ability, which might play a role in the depression of avoidance performance.

Further, the proposal (Vanderwolf, 1962) that medial thalamic lesions impair the initiation of voluntary movement implies a generalized effect on a variety of behaviors. However, large medial thalamic lesions do not impair a rat's ability to run toward food or water (Replogle, 1960; Vanderwolf, 1962, 1967), behaviors usually regarded as "voluntary."

The following experiments attempt to clarify these points.

\section{EXPERIMENT 1}

Subjects and Procedure

The Ss were 31 naive hooded rats, weighing at least $300 \mathrm{~g}$ at the start of the experiments. Large lesions were made by electrolysis in the medial thalamic area in 16 rats. Fifteen control rats were subjected to a sham surgical operation.

Two weeks or more after surgery, all rats were trained in a three-choice discrimination apparatus. Rats were permitted either to avoid or escape from a metal grid floor (which could supply a current of about $1.5 \mathrm{~mA}$ ) by nunning to a frosted glass screen, illuminated from behind by a $25-\mathrm{W}$ light. Two additional screens remained dark. In a second phase of the experiment, rats were trained to choose a dark screen from among two lighted screens. The spatial position of dark and lighted screens was varied randomly from trial to trial. After the start of a trial, a rat was allowed $5 \mathrm{sec}$ to avoid before shock was presented. Up to 100 trials were given in a single session with an intertrial interval of $15 \mathrm{sec}$.

\section{Results}

In the condition in which rats learned to approach a lighted screen, nine control rats reached a $90 \%$ correct criterion ( 9 correct in 10 trials) in discrimination performance after a mean of 23.2 trials; 10 medial thalamus-damaged rats reached this criterion after a mean of 39.6 trials (n.s.). The control rats averaged 19.6 errors; the thalamus-damaged rats averaged 37.3 errors ( $p<.05$, Mann-Whitney test). The control rats all made avoidance responses and seven of the nine rats reached a $90 \%$ level of performance (after an average of 41.6 trials) The remaining two control rats did not reach criterion in 100 trials. None of the thalamus-damaged rats made a single avoidance response in 100 trials.

In the condition in which the rats were trained to run toward a darkened screen, both discrimination and avoidance performance appeared to be poorer. Control rats $(\mathrm{N}=6)$ reached a $90 \%$ correct criterion in discrimination performance after an average of 57.7 trials and 70.8 errors. Thalamus-damaged rats $(\mathrm{N}=6)$ reached the same level of performance after 54.0 trials and 59.5 errors. The two groups do not differ significantly. None of the rats reached a $90 \%$ criterion of avoidance performance in 100 trials, although one control rat made a small number of successful avoidance responses.

Thus, when the rats were taught to run to a lighted screen, thalamus-damaged rats were mildly impaired in discrimination performance but made no avoidance responses whatever. When the rats were taught to run to a darkened screen, even the normal rats failed to avoid and both groups exhibited an equal rate of acquisition of the brightness-discrimination habit.

\section{EXPERIMENT 2}

Subjects and Procedure

The Ss were 37 naive hooded rats, weighing at least $300 \mathrm{~g}$ prior to surgery. Twenty-one received large electrolytic lesions of the medial thalamus; 16 served as operate control rats. Two weeks or more after surgery, rats were placed in individual cages on a table behind a one-way screen. A buzzer and two 60-W light bulbs (normally unlighted) were placed about $2 \mathrm{ft}$ above the cages. About $24 \mathrm{~h}$ later, at a time when the animals were lying down, the buzzer and lights were turned on for a period of $5 \mathrm{~min}$. The latency of the first rearing response (forepaws lifted off cage floor, head movements and sniffing) was recorded with a stopwatch. This procedure was repeated daily on 4 successive days. Experimental and control rats were tested together in sets of four.

\section{Results}

All rats, except one control rat which did not respond at all, displayed rearing behavior within $5 \mathrm{~min}$ on at least one of the 4 test days. Mean latency was $73 \mathrm{sec}$ for sham-operate rats $(\mathrm{N}=16)$, and $116 \mathrm{sec}$ for medial thalamus-damaged rats $(\mathrm{N}=21)$ ( $p=.012 ;$ Mann-Whitney test)

\section{EXPERIMENT 3}

It has been reported previously that medial thalamus-damaged rats explore an unfamiliar box more actively than normal (Vanderwolf, 1962). This was confirmed in a supplementary experiment. Nine sham-operate rats and eight rats with medial thalamic lesions (these rats were later used in Experiment 2) were placed, one at a time, in an unfamiliar empty box and watched for $9 \mathrm{~min}$ through a one-way screen. The behavior in progress at the instant of occurrence of each of a series of clicks, occurring every $6 \mathrm{sec}$, was recorded (see Bindra \& Blond, 1958). The control rats were rearing on an average of 27 such occasions while the experimental rats were rearing on an average of 42 occasions ( $p<.002 ;$ Mann-Whitney test). On the other hand, the normal rats were observed "freezing" (motionless but alert, as indicated by widely opened eyes) on an average of 12.8 occasions; medial thalamus-damaged rats averaged only 1.0 occasions $(p<.002 ;$ Mann-Whitney test).

Thus, in an unfamiliar situation, thalamus-damaged rats freeze less but rear more than control rats. EXPERIMENT 4

Subjects and Procedure

Fifty-nine rats (31 with chronic medial thalamic lesions and 28 sham-operate control rats) have been subjected to a "platform test" on several occasions. Rats were placed in groups on a table for at least an hour per day for 4 days or more (in different replications) in order to habituate freezing responses. Next, a small ( 4 x 6 in.) platform was introduced, placed at the same height as the table, but leaving a space of $3 \mathrm{in}$. between it and the table edge. Rats were removed individually from their cages, placed on the small platform, and the time taken to cross the 3-in. gap to the familiar table-top (with all four feet) was recorded. In some cases, testing was preceded by one 
Table 1

Mean Response Latency (Sec) on Platform Test Einder Three Conditions (Maximum Permitted Latency $300 \mathrm{Sec}$ )

\begin{tabular}{|c|c|c|c|c|c|c|c|c|c|}
\hline & $\begin{array}{l}\text { Following } \\
\text { removal } \\
\text { from } \\
\text { home cage }\end{array}$ & p & $\begin{array}{c}\text { After } \\
5 \text { min } \\
\text { exploration }\end{array}$ & $\mathbf{p}$ & $\begin{array}{l}\text { Following } \\
\text { removal } \\
\text { from } \\
\text { home cage }\end{array}$ & $p$ & $\begin{array}{c}\text { After } \\
30 \mathrm{sec} \\
\text { swimming }\end{array}$ & $p$ & $\begin{array}{l}\text { Iollowing } \\
\text { removal } \\
\text { from } \\
\text { home cage }\end{array}$ \\
\hline $\begin{array}{l}\text { Sham opera } \\
\text { group } \\
(\mathrm{N}=12)\end{array}$ & 22.8 & $<.01$ & 3.1 & $<.01$ & 133 & N.S. & 5.2 & $<.01$ & 22.9 \\
\hline $\begin{array}{l}\text { Thalamic } \\
\text { lesion group } \\
N=10 \text { ) }\end{array}$ & p 133.5 & $<.01$ & 56.6 & $<.01$ & 176.3 & $<.01$ & 35.9 & $<.01$ & 118.0 \\
\hline
\end{tabular}

or another experimental treatment. Testing was done in the afternoon when the rats were usually resting quietly in their cages. Experimental and control rats were always tested in a mixed order.

\section{Results}

Crossing latencies under various conditions are summarized in Tables 1 and 2. Data were analyzed with the help of the Friedman, Wilcoxon, and Mann-Whitney nonparametric tests (Siegel, 1956). Normal rats usually leave the small platform within $60 \mathrm{sec}$; thalamus-damaged rats exhibit longer latencies and of ten fail to cross within $15 \mathrm{~min}$. This difference is highly significant. Thalamus-damaged rats cross the 3-in. space easily and rapidly when they attempt to do so. However, they usually lie or stand motionless on the small platform for long periods.

Various procedures which make rats active tend to reduce response latency in the test in both normal and medial thalamus-damaged rats. Tables 1 and 2 show the effects of $5 \mathrm{~min}$ exploration of a novel environment, $30 \mathrm{sec}$ swimming in a bucket of water at room temperature, and hunger produced by restricted feeding for 2 days.

\section{Anatomical Control}

After completion of the experiments, all thalamus-damaged rats were sacrificed. Coronal brain sections were prepared through the extent of the lesion and stained with either thionin or haematoxylin and eosin. The lesions appeared similar to those described previously (Vanderwolf, 1962,

1964), destroying mainly the medial, midline, and intralaminar nuclei, and the habenula.

As an additional check on lesion placement, all animals (except those in Experiment 1) were given 30 trials on a one-way avoidance task (Vanderwolf, 1962) prior to sacrifice. Sham-operate rats performed well, making from 21 to 27 avoidance responses. Over half the thalamus-damaged rats did not avoid at all and the remaining animals made only a small number of successful responses.

It is perhaps worth pointing out that, although the apparatus described in Experiment 1 tests one-way avoidance performance, both normal and thalamus-damaged rats do not avoid shock in it as readily as in the simple one-way apparatus.

\section{DISCUSSION}

Rats with medial thalamic lesions were unable to avoid shock but could acquire a brightness discrimination habit (based on escape performance) in a situation which tested both of these abilities simul taneously. This supports a previous proposal that the avoidance deficit exhibited by these animals is not primarily the result of an inability to learn. Some degree of learning deficit may be present, however, since the thalamus-damaged rats acquired the discrimination habit somewhat more slowly than normal (under one of the two conditions employed) and since medial thalamic damage has been found to impair
Table 2

Effect of Hunger on Response Latency (in Sec) in Platform Test (Maximum Permitted Latency $900 \mathrm{Sec}$ )

\begin{tabular}{ccccc}
$\begin{array}{c}\text { Following } \\
\text { removal from } \\
\text { home cage }\end{array}$ & $\begin{array}{c}\text { Following } \\
\text { removal from } \\
\text { home cage }\end{array}$ & $p$ & $\begin{array}{c}\text { After 2 days } \\
\text { on feeding } \\
\text { schedule }\end{array}$ & $\begin{array}{c}\text { Following } \\
\text { removal from } \\
\text { home cage }\end{array}$ \\
\hline
\end{tabular}

\section{Sham operate}

group 40.0

26.9

N.S.

9.8

N.S.

$14.3^{*}$

$=16$

Thalamic

lesion grou

522.0

524.6

$<.01$

278.3

$<.01$

484,4

* Overall decline in latency is significant in sham operate group $(p<.02)$. performance in complex mazes, though not in simple mazes or runways (see references in introduction).

An interpretation of many of the effects of medial thalamic lesions is suggested by the observation that operate rats are hyperactive during the inmediate postoperative period. Many rats walk or run almost continuously for several hours. This phase is followed by a period of almost total absence of spontaneous movement which persists for days, but from which the rats gradually recover. The initial hyperactivity suggests an irritative effect on a movement-controlling system due to injury discharges, etc. (seizures sometimes accompany the hyperactivity). The succeeding akinesia may be a true deficit phenomenon which is gradually compensated, so that within $2-3$ weeks only traces of it persist and special tests are required (e.g., Experiments 2 and 4 ) to show that the initiation of movement is abnormal.

It might be suggested that the long latency performance in the platform test (Experiment 4) is due to an increased tendency to freeze on the part of medial thalamus-damaged rats. However, the rats did not appear fearful. Counts of fecal boluses were made in part of the experiment, and, if anything, the experimental rats defecated less than mrmal, as previously found ( $\mathrm{V}$ anderwolf, 1962). During exploration of an unfamiliar box, the thalamus-damaged rats tended to freeze less than normal (Experiment 3). However, in an avoidance test, these rats exhibit an exaggerated tendency to freeze (as well as defecation, vocalization, etc.). This suggests that medial thalamic lesions raise the threshold of the central fear mechanism as well as reducing the activity of mechanisms concerned with production of movement, relative to the activity of mechanisms concerned with freezing behavior. The imbalance between the latter systems can be restored to some extent by septal lesions or electroconvulsive shock (Vanderwolf, 1964, 1967).

The finding that prior motor activity of various types shortens response latency in the platform test, could be due to a "warm-up" of central mechanisms concerned with the production of voluntary movement. These effects may be related to the improvement in avoidance performance produced by pretest exploration or handling, food deprivation, or amphetamine-like drugs (Vanderwolf, 1966; Wahlsten et al, 1968). "Warm-up" phenomena may also be responsible for the finding that initiation of movement is normal in medial thalamus-damaged rats in approach tests, since the rats are likely to be active immediately before the actual test in such cases. 


\section{REFIRENCES}

(ARDO, B. Rapports entre le niveau de vigilance et le cunditionnement chez l'animal. Journal de Physiologic, Paris, 1961, 53, 1-212.

BINDR A. D.. \& BI.OND, J. A time-sample method for measuring general ativity and its components. Canadian Journal of Psychology, 1958. 12, 74-76.

DLILACOUR, J., ALBE-IISSSARD, D., \& LIBOUBAN, S. Role chez le rat de deux noyaux thalamiques dans le conditionnement instrumental. Neuropsychology, 1966, 4. 101-112.

GROSS, C. G., CHOROVER, S. L., \& COHEN, S M. Caudate, cortical, hippocampal and dorsal thalamic lesions in rats: Alternation and Hcbb-Williams maze performance. Neuropsychology, 1965, 3, 53-68.

REPLOGLE, A. Motivational effects of lesions in the thalamus. Unpublished M.A. thesis, McGill University, 1960.

SIEGEL, S. Nonparametric statistics for the behavioral sciences. New York: McGraw-Hill, 1956.

THOMPSON, R. Thalamic structures critical for retention of an avoidance conditioned response in rats. Journal of Comparative \& Physiological Psychology, 1963, 56, 261-267.

VANDERWOLF, C. H. Medial thalamic functions in voluntary behaviour. Canadian Journal of Psychology, 1962, 16, 318-330.
VANDERWOLF, C. H. The effect of medial thatamic lesions on previously established fear-motivated behaviour. Canadian Journal of Psychology, 1963,17, 183-187.

VANDI:RWOLI, C. H. Effect of combined medial thalamic and septal lesions on active-avoidance behavior. Journal of Comparative \& Physiological Psychology, 1964, 58, 31-37.

VANDERWOLF, C. H. Warm-up effects in the avoidance performance of rats with medial thalamic lesions. Animal Behaviour, 1966, 14, 425-429.

VANDERWOLF, C. H. Effects of experimental diencephalic damage on food hoarding and shock avoidance behavior in the rat. Physiology \& Bchavior, 1967, 2, 399-402.

VANDERWOLF, C. H. Recovery from large medial thalamic lesions as a result of clectroconvulsive therapy. Journal of Neurology, Neurosurgery \& Psychiatry, 1968, $31,67.72$.

WAHLSTEN, D., COLE, M., \& SHARP, D. Facilitation of bar-press avoidance by handling during the intertrial interval. Joumal of Comparative \& Physiological Psychology, 1968, 65, 170-175.

WARREN, J. M., \& AKERT, K. Impaired problem solving by cats with thalamic lesions. Joumal of Comparative \& Physiological Psychology, 1960 57, 207-211.

\section{A comparison of morphine and food deprivation on wheel activity}

RONALD C. TROST $\dot{T}^{l}$ and PAUL D. KNOTT, University of Denver, Denver, Colo. 80210

Morphine-addicted rats, tested under four different abstinence periods on wheel activity, showed no changes as did a group undergoing analogous periods of food deprivation. Several hypotheses are discussed concerning why morphine withdrawal might be expected to differ from hunger in its effect on activity.

Numerous studies have suggested that certain analogies exist between a morphine need state and other more classically manipulated motives, such as hunger. When, for example, morphine is abruptly withdrawn from an addicted animal, $S$ will (a) learn a new response for morphine reward (e.g., Thompson \& Ostlund, 1965), (b) show classical conditioning to the environmental cues paired with this situation (e.g., Wikler \& Pescor, 1967), and (c) exhibit an increase in a variety of behaviors which are consistent with current notions of restless activity (e.g., Martin, Wikler, Eades, \& Pescor, 1963). The last analogy may be questioned, however, on the
In that food deprivation leads to a decrease in body temperature and typically produces an increase in whee] activity, it is surprising that no attempt has been made to establish the contingencies which may exist between morphine privation and wheel performance since hypothemia has repeatedly been observed as a symptom of narcotic withdrawal (e.g., Martin et al, 1963). Accordingly, this experiment was designed to assess the effects of both food and morphine abstinence on wheel activity as a function of four different deprivation periods in order to determine the nature of the similarities between the two "motive" states with respect to this measure.

\section{METHOD}

Subjects were 30 experimentally naive male hooded rats of the Long-Evans strain. At the beginning of the experiment, they ranged between $80-100 \mathrm{~g}$ in weight and were 35 days old.

Thirty activity wheels, $15 \times 41 / 2$ in., with floors of $1 / 2$-in. wire mesh, were mounted on a large rack, 10 wheels per axel. Each wheel was provided with a simple mechanical counter and a racheting device which allowed the wheels to rotate in one direction only.

The Ss were housed in a separate room in $7 \times 10 \times 16$ in. cages, three per cage. Extraneous noise and stimulation were kept minimal during the entire experiment in both the home and testing environments, and indirect illumination was provided at all times by two 100 -W flourescent fixtures.

Beginning at age 35 days, each $S$ was handled every day until docile. Fifteen Ss were then randomly assigned to the drug-deprived group (Dd) and the food-deprived group (Fd). Group Dd was injected with an initial dose of $5 \mathrm{mg} / \mathrm{kg}$ ip of morphine sulfate twice daily at $9 \mathrm{a} . \mathrm{m}$. and 9 p.m. and received ascending doses bi-weekly until stabilization at $200 \mathrm{mg} / \mathrm{kg} /$ day on the $35 \mathrm{th}$ day. The volume of solution for each animal was kept constant during this time on a weight basis and usually ranged between .2 to $.3 \mathrm{cc}$ for a given S. Dilution of morphine sulfate within this volume increased every $3 \frac{1}{2}$ days. A similar schedule and dosage rate has been shown elsewhere to addict rats to morphine (Martin et al, 1963), and was maintained until the testing phase 32 days later. Group Fd was treated in a similar manner except for injections of $0.9 \%$ aqueous solution of sodium chloride in place of morphine sulfate at the same time and at volumetrically equivalent amounts. During this time, food and water were ad lib.

Immediately following a week of dosage stabilization, an adaptation phase was begun whereby each $\mathrm{S}$ was assigned to any one of 30 available activity wheels for $12 \mathrm{~h}$ per day. At the end of this period, $\overline{\mathrm{X}}$ revolutions/h 